\title{
Effect of Atrial Natriuretic Peptide on Diastolic Filling in the Stage 21 Chick Embryo
}

\author{
NORMAN HU, AMY L. HANSEN, EDWARD B. CLARK, AND BRADLEY B. KELLER \\ National Institutes of Health SCOR in Pediatric Cardiovascular Diseases, University of Rochester School \\ of Medicine and Dentistry, Rochester, New York 14642
}

ABSTRACT

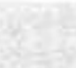

Atrial natriuretic peptide (ANP) exerts hemodynamic effects by direct venodilation in the chick embryo. We hypothesized that ANP-induced venodilation affects ventricular diastolic filling resulting in reduced ventricular preload. Chick ANP $(0.1 \mu \mathrm{g}$ in $10 \mu \mathrm{L}$ of normal saline) was suffused onto the vitelline vascular bed in stage $21\left(3 \frac{1}{2} \mathrm{~d}\right)$ chick embryos. Equivalent aliquots of normal saline were suffused as sham controls, and normal embryos received no suffusion. We measured simultaneously dorsal aortic blood velocity and atrioventricular blood velocity with a $20-\mathrm{MHz}$ pulsed-Doppler velocity meter. Analog wave forms were digitally sampled at $500 \mathrm{~Hz}$, and the dorsal aortic crosssectional area was used to calculate dorsal aortic blood flow. Passive ventricular filling volume equaled dorsal aortic stroke volume multiplied by the fraction of passive area; active filling volume equaled dorsal aortic stroke volume multiplied by the fraction of active area. Data were summarized as mean \pm SEM ( $n \geq 7$ per group) and analyzed by analysis of variance. Cycle
\end{abstract}

ANP is one member of a family of vasoactive hormones with conserved sequences across species, and at least three protein subclasses and three receptors have been identified (1). In contrast to its localized synthesis in the atrial appendages of the healthy mature heart, during primary cardiac morphogenesis, "atrial" natriuretic peptide is widely distributed in the embryonic myocardium $(2,3)$. Of note, the resynthesis of ANP is a useful marker for myocyte hypertrophy (4). In the embryonic circulation, ANP exerts its hemodynamic effect by direct vasodilation, decreasing venous and arterial pressures (5). The microvascular mechanism of the ANP response may be through vascular permeability or by altered Starling forces across the capillary beds $(6,7)$. Because the early developing cardiovascular system is not innervated (8) and the kidneys are not yet developed (9), cardiovascular function is sensitive to mechanisms that alter hemodynamic load.

We use the technique of pulsed-Doppler measurement of blood velocity and flow to define embryonic diastolic function $(10,11)$. The combination of simultaneous AV and dorsal

Received May 17, 1994; accepted November 18, 1994.

Correspondence: Norman Hu, University of Rochester, Pediatric Cardiology, Box 631, 601 Elmwood Ave., Rochester, NY 14642.

Supported by National Institutes of Health Grant P50-HL51498. lengths were similar in ANP-suffused, sham control, and normal embryos. Dorsal aortic blood flow decreased from $0.49 \pm 0.04$ $\mathrm{mm}^{3} / \mathrm{s}$ at baseline to $0.27 \pm 0.05 \mathrm{~mm}^{3} / \mathrm{s}$ at $4 \mathrm{~min}$ post-ANP suffusion $(p<0.05)$ and was unchanged in sham control and normal embryos $(p>0.05)$. Passive ventricular filling was reduced by ANP suffusion, whereas active filling was unaffected, resulting in a decreased passive/active filling ratio from $0.64 \pm$ 0.07 at baseline to $0.32 \pm 0.08$ at $4 \mathrm{~min}$ in ANP-suffused embryos $(p<0.05)$. Passive/active ratio was unchanged in sham control and normal embryos. Thus, ANP-mediated vasodilation reduces cardiac output via decreased passive ventricular filling in the embryonic heart. (Pediatr Res 37: 465-468, 1995)
Abbreviations
ANP, atrial natriuretic peptide
$\mathbf{A V}$, atrioventricular

aortic blood flow profiles accurately defines passive and active ventricular filling volumes (10). Embryonic cardiovascular performance can be defined during normal growth and development and after interventions that alter cycle length or loading conditions $(12,13)$. Since the embryonic ventricle is relatively noncompliant, embryonic cardiovascular function is extremely sensitive to diastolic filling time and to loading conditions (12).

The embryonic ventricle responds to alterations in preload via a linear relationship between end-diastolic volume and stroke volume (12). In contrast to the mature circulation, the embryonic cardiovascular system lacks a heart rate response to compensate for reduced ventricular preload. We therefore hypothesized that ANP-induced venodilation would alter passive ventricular diastolic filling, resulting in reduced ventricular preload and subsequent reduced cardiac output. The sensitivity of the embryonic cardiovascular system to exogenous ANP further substantiates the role of constitutive ANP in the regulation of the preinnervated embryonic circulation.

\section{METHODS}

Fertile white Leghorn chicken eggs were incubated blunt end up in a forced-draft $38.5^{\circ} \mathrm{C}$ incubator to Hamburger- 
Hamilton stage 21 (31/2 d) (14). We measured simultaneously dorsal aortic blood flow and $\mathrm{AV}$ blood velocity with a $20 \mathrm{MHz}$ pulsed-Doppler velocity meter using $0.5-\mathrm{mm}$ piezoelectric crystals $(10,11)$. Analog wave forms were digitally sampled at $500 \mathrm{~Hz}$ with an analog/digital data acquisition system. Data were stored in a 51/4-inch 150 Megabytes Bernoulli cartridge (Iomega, Roy, UT). After acquiring 1 min of baseline velocity, we suffused $0.1 \mu \mathrm{g}$ of synthetic chicken ANP (Sigma Chemical Co., St. Louis, MO) in $10 \mu \mathrm{L}$ of normal saline to the vitelline vascular bed and observed the data for $4 \mathrm{~min}$. We selected the ANP dose previously reported to produce venodilation in the chick embryo (5). Sham embryos were suffused with equivalent aliquots of normal saline, and normal embryos received no suffusion. The ANP solution and the normal saline were warmed to embryo temperature with a water bath $\left(37^{\circ} \mathrm{C}\right)$. We monitored embryo temperature with a $3.0-\mathrm{mm}$ flat disc thermistor placed on the surface of the vitelline vascular bed adjacent to the embryo and maintained constant embryo temperature using a warming lamp.

Passive filling $(\mathrm{P})$ was defined in the AV blood velocity profile from end-systole to the onset of the a-wave, and active filling (A) from the onset of the a-wave to the onset of systole (Fig. 1). Cycle length was measured as the time between the consecutive dorsal aortic blood velocities. Dorsal aortic and both passive and active AV velocity profiles were integrated over time using a wave form analysis software (Datapac, RUN Technologies, Laguna Nigual, CA). Blood flow was calculated from the integral of dorsal aortic velocity and the aortic cross-sectional area. Passive ventricular filling volume equaled dorsal aortic stroke volume multiplied by the passive area fraction, and active ventricular filling volume equaled dorsal aortic stroke volume multiplied by the active area fraction (10).

Seven or more embryos were measured from ANP-suffused, sham, and normal embryos. For each cmbryo, we analyzed at least 15 consecutive cycles at the beginning of each minute. The data were summarized as mean \pm SEM and statistical compared one-way and two-way analysis of variance. Significance level was defined as a $p$ value of less than $5 \%(p<0.05)$.

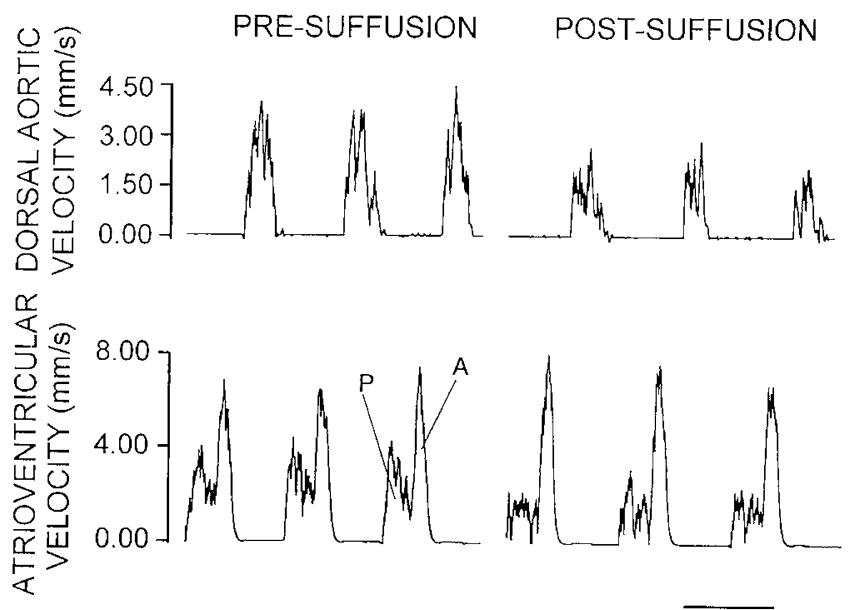

$\overline{400 \mathrm{~ms}}$

Figure 1. Representative presuffusion and 4-min postsuffusion simultaneous dorsal aortic and AV velocity analog wave forms of an ANP-trcated stage 21 chick cmbryo ( $P$, passive filling; $A$, active filling). Note the reduction of peak aortic velocity and passive filling velocity following ANP suffusion.

\section{RESULTS}

Cycle lengths were similar in ANP-suffused, sham control, and normal embryos throughout the time period (Fig. 2). After $4 \mathrm{~min}$, dorsal aortic blood flow decreased by $46.9 \%$ in ANPsuffused embryos $(p<0.05)$, but was similar in sham control and normal embryos $(p>0.05$, Table 1$)$. Dorsal aortic stroke volume reflected similar changes in the ANP-treated, sham control, and normal embryo groups (Fig. 3).

Passive AV flow decreased from $0.28 \pm 0.01 \mathrm{~mm}^{3} / \mathrm{s}$ at baseline to $0.05 \pm 0.02 \mathrm{~mm}^{3} / \mathrm{s}$ at $4 \mathrm{~min}$ postsuffusion in ANP-suffused embryos $(p<0.05)$ (Fig. 4). Passive AV flows were similar to baseline values sham control and normal embryo groups after $4 \mathrm{~min}$. Passive AV filling volumes reflected similar changes as in the passive AV flows of the ANP-treated, sham control, and normal embryo groups (Table 2).

Active AV fiows and filling volumes were similar among the ANP-suffused, sham control, and normal embryos (Fig. 4). Passive/active filling ratio decreased from $0.64 \pm 0.07$ at baseline to $0.32 \pm 0.08$ at $4 \mathrm{~min}$ in ANP-suffused embryos $(p<0.05)$ (Fig. 5). Passive/active filling ratio was unchanged in sham and normal embryos.

\section{DISCUSSION}

As has been noted in several studies of experimentally altered embryonic cardiovascular function, heart rate did not increase in response to decreased ventricular filling. In contrast, the mature cardiovascular system adjusts heart rate, myocardial contractility, and loading condition to main cardiac output. Before functional autonomic innervation, the embryonic myocardium lacks the ability to acutely alter heart rate in response to altered hemodynamic conditions (13). Likewise, early in primary cardiac morphogenesis the embryonic contractile response is limited by an underdeveloped calcium handling system and incomplete myofiber assembly (15). When considered from the opposite perspective, the lack of acute heart rate and contractility adaptive responses highlights the importance of ventricular preload and afterload in the regulation of embryonic cardiovascular performance.

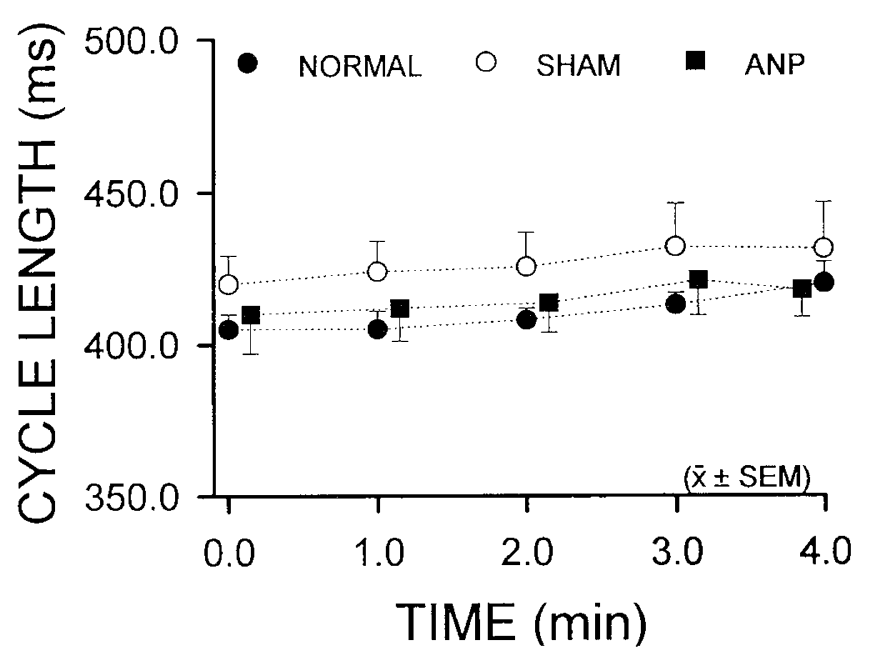

Figure 2. Cycle length vs time for ANP-suffused, sham control, and normal embryos. ANP suffused at time $=0$. Data presented as mean $\pm \mathrm{SEM}$. 
Table 1. Dorsal aortic blood flow vs time for the ANP-suffused, sham control, and normal embryo groups

\begin{tabular}{cccc}
\hline $\begin{array}{c}\text { Time } \\
(\mathrm{min})\end{array}$ & $\begin{array}{c}\text { ANP } \\
\left(\mathrm{mm}^{3} / \mathrm{s}\right)\end{array}$ & $\begin{array}{c}\text { Sham } \\
\left(\mathrm{mm}^{3} / \mathrm{s}\right)\end{array}$ & $\begin{array}{c}\text { Normal } \\
\left(\mathrm{mm}^{3} / \mathrm{s}\right)\end{array}$ \\
\hline 0 & $0.44 \pm 0.02$ & $0.43 \pm 0.05$ & $0.44 \pm 0.01$ \\
1 & $0.39 \pm 0.03$ & $0.44 \pm 0.02$ & $0.42 \pm 0.02$ \\
2 & $0.27 \pm 0.05^{*}$ & $0.43 \pm 0.03$ & $0.43 \pm 0.02$ \\
3 & $0.24 \pm 0.06^{*}$ & $0.41 \pm 0.04$ & $0.40 \pm 0.02$ \\
4 & $0.23 \pm 0.06^{*}$ & $0.42 \pm 0.07$ & $0.42 \pm 0.01$ \\
\hline
\end{tabular}

Data summarized as mean \pm SEM.

$* p<0.05$.

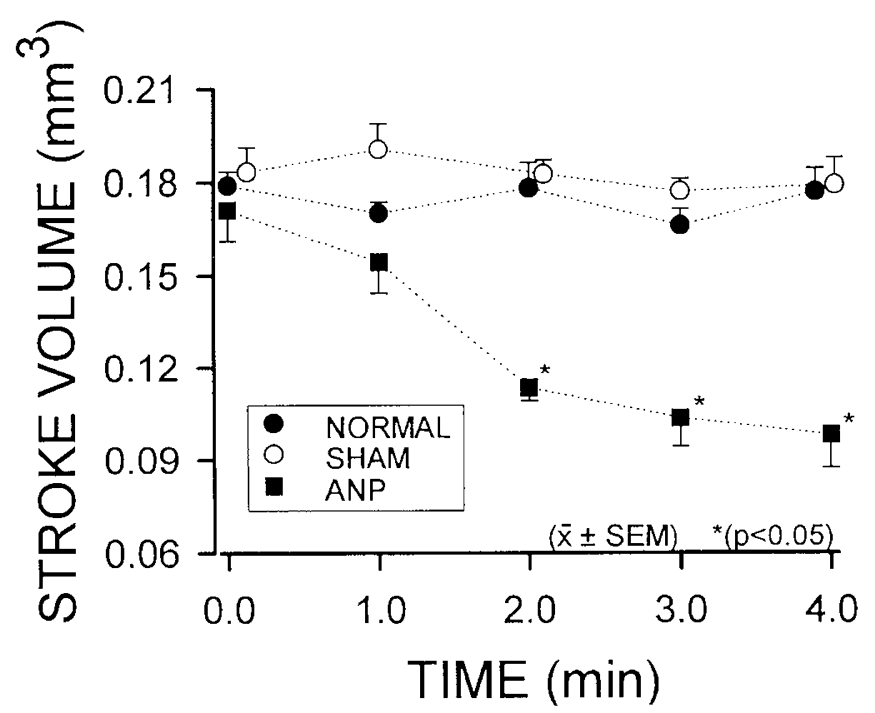

Figure 3. Dorsal aortic stroke volume vs time for ANP-suffused, sham control, and normal embryos. Data presented as mean \pm SEM. Note that dorsal aortic stroke volume was reduced only in the ANP-suffused embryos.

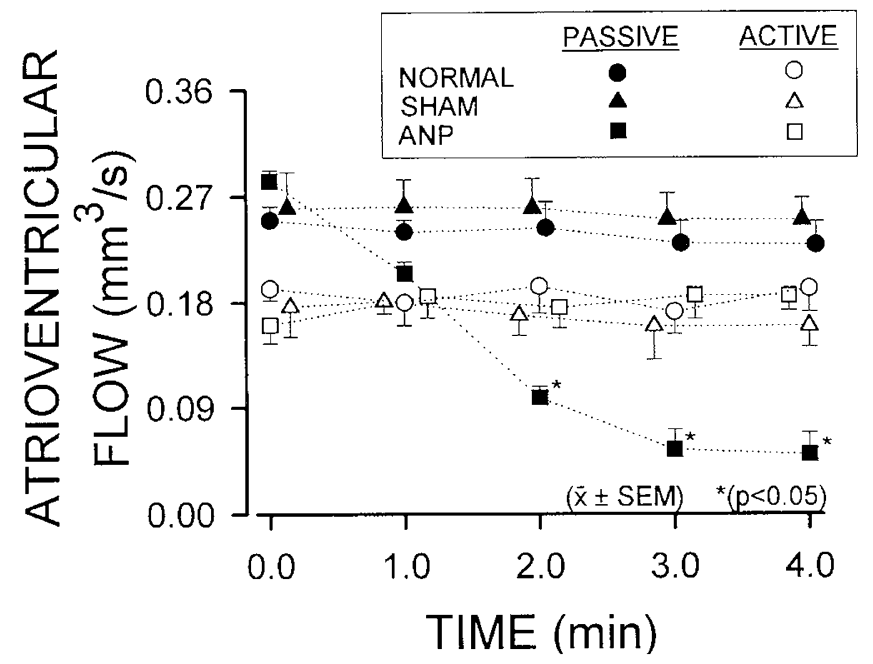

Figure 4. AV blood flow $v$ s time for ANP-suffused, sham control, and normal embryos. Solid symbols represent passive flow and open symbols represent active flow. Data presented as mean \pm SEM. Note that passive AV blood flow was reduced only in the ANP-suffused embryos. Active AV flow was unaffected by ANP suffusion.

Our finding that ANP-mediated vasodilation reduces passive ventricular filling underscores the importance of veno/atrial coupling and atrial conduit function in determining ventricular preload. The embryonic heart depends on diastolic filling time and both passive and active filling volumes to maintain ade-
Table 2. Passive ventricular filling volume vs time for ANP-suffused, sham control, and normal embryo groups

\begin{tabular}{cccc}
\hline $\begin{array}{c}\text { Time } \\
(\mathrm{min})\end{array}$ & $\begin{array}{c}\text { ANP } \\
\left(\mathrm{mm}^{3}\right)\end{array}$ & $\begin{array}{c}\text { Sham } \\
\left(\mathrm{mm}^{3}\right)\end{array}$ & $\begin{array}{c}\text { Normal } \\
\left(\mathrm{mm}^{3}\right)\end{array}$ \\
\hline 0 & $0.11 \pm 0.01$ & $0.11 \pm 0.01$ & $0.10 \pm 0.01$ \\
1 & $0.08 \pm 0.01$ & $0.11 \pm 0.01$ & $0.10 \pm 0.01$ \\
2 & $0.04 \pm 0.01^{*}$ & $0.11 \pm 0.01$ & $0.10 \pm 0.01$ \\
3 & $0.02 \pm 0.01^{*}$ & $0.11 \pm 0.01$ & $0.10 \pm 0.01$ \\
4 & $0.02 \pm 0.01^{*}$ & $0.11 \pm 0.01$ & $0.10 \pm 0.01$ \\
\hline
\end{tabular}

Data summarized as mean \pm SEM.

$* p<0.05$.

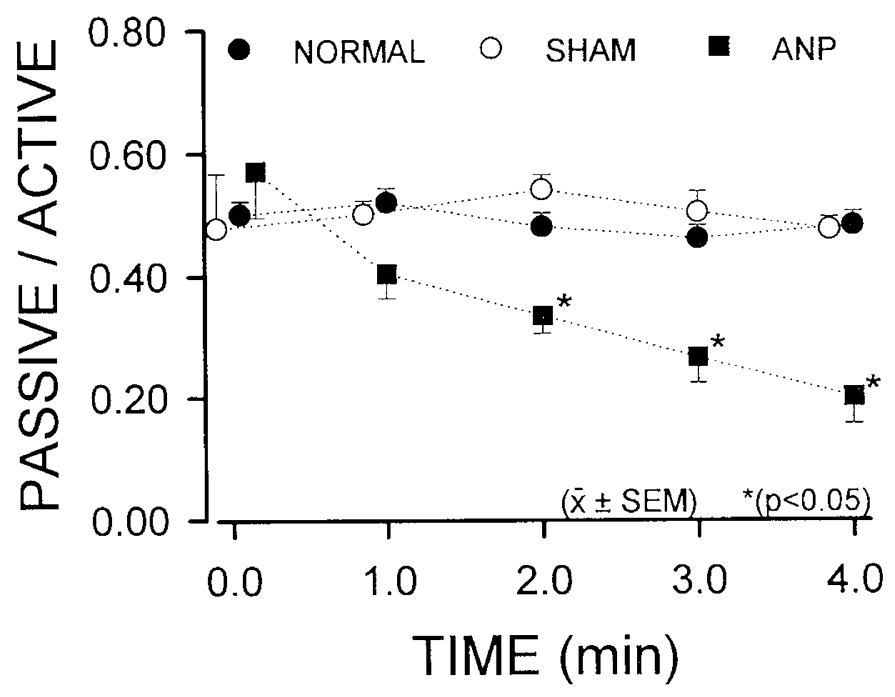

Figure 5. Passive/active filling ratio vs time for ANP-suffused, sham control, and normal embryos. Data presented as mean \pm SEM. Note that the passive/ active ratio declined only for ANP-treated embryos, consistent with reduced passive ventricular filling.

quate ventricular preload $(10,13)$. When cycle length is altered by the transient application of a thermal probe to the sinus venosus, end-diastolic volume is linearly related to diastolic filling time (13). Thus, mechanisms that regulate venous return to the atrium or the time available for blood to pass through the atrium into the ventricle will directly alter ventricular preload (16).

The reduction in passive filling noted after ANP treatment is not likely due to alterations in ventricular relaxation or the passive properties of the myocardium. ANP decreases calcium entry into myocardial cells (17), and thus, ANP might have resulted in accelerated relaxation and augmented filling. Direct calculations of the time constant of ventricular pressure decline is necessary to define altered relaxation rates. Likewise, ventricular pressure-volume relations are needed to define any effect of ANP on passive ventricular properties (12). However, as the passive properties of the embryonic myocardium are predominantly determined by cell-to-cell and extracellular matrix properties, it is unlikely that ANP has any acute effects on passive ventricular properties (18).

Our finding that active AV flow was unaffected by ANP treatment is further evidence that achieving maximal atrial volume may be less sensitive to veno/atrial coupling than is passive ventricular filling. At intrinsic heart rates, maximum atrial perimeter occurs before the completion of passive ven- 
tricular filling, and despite significant reductions in diastolic time, atrial maximal perimeter, shortening fraction, and peak active AV velocity are unaffected (19). Likewise, significant increases in diastolic filling time do not increase atrial maximal perimeter or shortcning fraction. Thus, the relatively noncompliant embryonic atrium is maximally "stretched" during normal states. Ventricular end-diastolic volume varies significantly depending upon diastolic filling time and loading conditions, and so in contrast to the mature myocardium, ventricular "stretch" may be the major determinant for ANP relcase in the developing circulation (20-22). Alternatively, wall stress may be important in determining ANP release, and then the relatively thicker and more compliant ventricular wall would tend to reduce transmitted stresses.

As the embryonic ventricular myocardium contains abundant ANP granules, the time course and extent of ventricular loading may influence the site and extent of ANP release. In the chick embryo, blood streams from the vitelline veins and duct of Cuvicr into the sinus venosus, and then through the developing right and left atria across the AV canal (23). These flow stream spiral within the developing ventricle, and then exit into the aortic sac and aortic arches. Ventricular growth rate is directly related to the extend of ventricular filling and ventricular hypoplasia results when filling is experimentally reduced by partial left atria ligation (24). In contrast, increased ventricular afterload produced by conotruncal banding results in accelerated ventricular growth and myocyte hyperplasia (25). Because ANP is a marker for myocyte hypertrophy in the mature heart, it is likely that local ANP synthesis is also unregulated during accelcrated ventricular growth. In the mature heart, the kinetics of the ANP secretory response to stretch suggest that the ventricle makes a greater contribution to the circulating level of ANP at the onset of cardiac pressure or volume overload (20-22). However, if the overload persists, the atrial contribution to ANP release becomes more significant.

The reduction of cardiac output was attributed to the ANPmediated dilation in venous bed that decreased preload and reduced blood return (AV filling) to the heart. Any changes in the afterload induced by ANP could be masked by the alteration in the preload. Similar studies such as instantaneous pressure-volume relationship of both atrium and ventricle are needed to define ANP kinctics in the developing circulation.

\section{REFERENCES}

1. Koller KJ, Goeddel DV 1992 Molecular biology of the natriuretic peptides and their receptors. Circulation 86:1081-1088

2. Omari BO, Nelson RJ, Robertson JM 1991 Effect of right atrial appendectomy on the release of atrial natriuretic hormone. J Thorac Cardiovasc Surg 102:272-279

3. Toshimori H, Toshimori K, Oura C, Matsuo H 1987 Immunohistochemical study of atrial natriurctic polypeptides in the embryonic, fetal and neonatal rat heart. Cell Tissue Res 248:627-633

4. Arai H, Nakao K, Saito Y, Morii N, Sugawara S, Yamada T, Itoh H, Shiono S, Mukoyama M, Ohkubo H, Nakanishi S, Imura H 1988 Augmented expression of atrial natriuretic polypeptide gene in ventricles of spontaneously hypertensive rats (SHR) and SHR-stroke prone. Circ Res 62:926-930

5. Nakazawa M, Kajio F, Ikeda K, Takao A 1990 Effect of atrial natriurctic peptide on hemodynamics of the stage 21 chick cmbryo. Pediatr Res 27:557-560

6. Johnson EH, Bennett SH, Goctzman BW 1992 The influcnce of pulsatile perfusion on the vascular propertics of the newborn lamb lung. Pediatr Res 31:349-353

7. Wagman AJ, Hu N, Clark EB 1990 Effect of changes in circulating blood volume on cardiac output and arterial and ventricular blood pressure in the stage 18,24, and 29 chick embryo. Circ Res 67:187-192

8. Pappano AJ 1977 Ontogenic development of autonomic ncuroeffector transmission and transmitter reactivity in cmbryonic and fetal hcarts. Pharmacol Rev 29:3-33

9. Bulter H, Jurlink BHJ 1987 An Atlas for Staging Mammalian and Chick Embryos. CRC Press, Boca Raton, FL

10. Hu N, Connuck DM, Keller BB, Clark EB 1991 Diastolic filling characteristics in the stage 12 to 27 chick embryo ventricle. Pediatr Res 29:334-337

11. Hu N, Clark EB 1989 Hemodynamics of the stage 12 to stage 29 chick embryo. Circ Res 65:1665-1670

12. Keller BB, Tinney JP, Hu N 1994 Embryonic ventricular diastolic and systolic pressure-volume relations. Cardiol Young 4:19-27

13. Casillas CB, Tinney JP, Keller BB 1994 Influence of acute alterations in cycle length on ventricular function in the chick embryo. Am J Physiol 267:H905-H911

14. Hamburger V, Hamilton HL 1951 A series of normal stages in the development of the chick embryo. J Morphol 88:49-92

15. Vetter R, Will H 1986 Sarcolemmal Na-Ca exchange and sarcoplasmic reticulum uptake in developing chick heart. J Mol Cell Cardiol 18:1267-1275

16. Yellin EL, Nikolic S, Frater RW 1990 Left ventricular filling dynamics and diastolic function. Prog Cardiovasc Dis 32:247-271

17. Stone JA, Backx PHM, ter Keurs HEDJ 1990 The effect of atrial natriuretic factor on force development in rat cardiac trabeculae. Can J Physiol Pharmacol 68:1247-1254

18. Taber LA, Keller BB, Clark EB 1992 Cardiac mechanics in the stage 16 chick embryo. J Biomech Eng 114:427-434

19. Campbell KA, Hu N, Clark EB, Keller BB 1992 Analysis of dynamic atrial dimension and function during early cardiac development in the chick embryo. Pediatr Res 32:333-337

20. Kinnunen P, Vuolteenaho O, Uusimaa P, Ruskoaho H 1992 Passive mechanical stretch release atrial natriuretic peptide from rat ventricular myocardium. Circ Res 70:1244-1253

21. Vardas PE, Walsh KP, Travill CM, Williams TDM, Ingram AM, Lightman SL, Sutton R 1989 Rclation of atrial natriuretic peptide release to atrial contraction. Am J Cardiol 63:753-755

22. Moe GW, Canepa-Anson R, Howard RJ, Armstrong PW 1991 Sequential changes in atrial pressures, dimensions, and plasma atrial natriuretic factor concentrations during volume loading in hemodynamically normal human subjects. J Lab Clin Med 117:528-534

23. Nishibatake M, Nakazawa M, Tomita H, Ikeda K, Takao A 1990 Imagc analysis of cardiac contraction in the early stages of the chick cmbryo. In: Clark EB, Takao A (eds) Developmental Cardiology: Morphogenesis and Function. Futura Publishing, Mount Kisco, NY, pp 305-314

24. Harh JY, Paul MH, Gallen. WJ, Friedberg DZ, Kaplan S 1973 Experimental production of hypoplastic left heart syndrome in the chick embryo. Am J Cardiol 31:51-56

25. Clark EB, Hu N, Frommelt P, Vandekieft JL, Dummett JL, Tomanek RJ 1989 Effect of increased ventricular pressure on heart growth in stage 21 chick cmbryo. Am J Physiol 257:H55-H61 